\title{
Minutes of August 2019 Council Meeting
}

\author{
Wednesday, August 29, 2019 \\ Washington, DC \\ Marriott Wardman Park
}

\section{MEMBERS PRESENT}

President: Rogers Smith (University of Pennsylvania); Past-President: Kathleen Thelen (Massachusetts Institute of Technology); President-Elect: Paula D. McClain (Duke University); Vice Presidents: Cathy Cohen (University of Chicago), Dvora Yanow (Wageningen University), Lisa Martin (University of Wisconsin, Madison); Treasurer: Thomas Pepinsky (Cornell University).

Council Members: Matt Barreto (University of California, Los Angeles); Adam Berinsky (Massachusetts Institute of Technology); Ann O'M. Bowman (Texas A\&M University); Joseph Carens (University of Toronto); Mark Crescenzi (University of North Carolina, Chapel Hill); Omar Encarnacion (Bard College); Lilly Goren (Carroll University); Lisa Garcia-Bedolla (University of California, Berkeley); Kristian Gleditsch* (University of Essex); Juliet Hooker (Brown University); Simon Jackman (University of Sydney); Julia Jordan-Zachery (University of North Carolina, Charlotte); Matthew Kocher (Johns Hopkins University); Lori Marso (Union College); Erin Richards (Cascadia College); Colleen Shogan (Library of Congress); Alberto Simpser (Instituto Tecnológico Autónomo de México); Valeria Sinclair-Chapman (Purdue University); Laura Sjoberg (University of Florida); Charles Smith (University of California, Irvine); Rocio Titiunik* (Princeton University); Renee Van Vechten (University of Redlands); Lisa Wedeen (University of Chicago); Christina Wolbrecht (University of Notre Dame).

APSA Staff: Steven Rathgeb Smith, Betsy Super, Dan Gibson, Kimberley Mealy, Vinaya Bharam, Larry Burner, Amanda Grigg, Jon Gurstelle, Casey Harrigan, Meghan McConaughey, Abby Paulson, Jason Sapia, Julia Walters.

*Attending via phone.

\section{INTRODUCTION}

APSA President Rogers Smith calls the 2019 APSA Fall Council Meeting to order.

\section{CONSENT AGENDA}

R. Smith introduces the March 2019 Council meeting minutes for Council approval. Van Vechten moves to approve the minutes; the motion is seconded and passes unanimously.

R. Smith introduces the 2020 record dates for Council approval. Goren moves to approve the 2020 record dates; the motion is seconded and passes unanimously.

R. Smith introduces the proposed changes to the PS and Perspectives editorial boards for Council approval. Richards notes that she appreciates the increase in institutional diversity on the $P S$ editorial board but suggests that community college faculty be utilized further. Goren agrees and encourages more institutional diversity on the Perspectives editorial board and on editorial boards overall. Yanow adds that due to the same persons serving on multiple boards, other persons are not asked to serve. She says a logical step is to limit the time served on editorial boards. R. Smith suggests communicating directly with editors about this issue and that the Publications Committee will address questions of editorial board diversity and service limits. S. Smith notes that an APSA alleditors meeting is planned for later in the week and the issue will be discussed then. C. Smith moves to approve the editorial boards as presented; motion is seconded and passes with two abstentions.

\section{PRESIDENT'S REPORT}

R. Smith reports on recent association activities and accomplishments to update the Council. R. Smith begins by thanking the Council, Executive Committee, and APSA staff for their service over the past year. R. Smith praises APSA for its work on protecting academic freedom and expanding policies regarding harassment and bullying. $\mathrm{He}$ provides an update on his Presidential Task Force, saying that seven unique initiatives are currently underway and the hope is to institutionalize those initiatives during his time as past-president.

\section{EXECUTIVE DIRECTOR'S REPORT}

APSA Executive Director Steven Rathgeb Smith introduces updates on association programming and operations to provide information to the Council. He brings attention to developments at the 2019 APSA Annual Meeting, including recordbreaking attendance, increased panels, a second year of TLC-at-APSA, a record number of travel grants, and the issuing of dozens of press passes. S. Smith celebrates the 5oth anniversary of the Minority Fellows Program. He reports that APSA membership numbers increased through the first part of 2019, with membership numbers topping 12 ,000 for the first time since 2016. Section membership has also increased. S. Smith draws attention to an APSA collaboration with other political science associations on an international teaching and learning conference that took place in Brighton, England. S. Smith also introduces APSA Preprints, which had a soft launch in spring 2019 and launches officially during the 2019 APSA Annual Meeting. Wolbrecht adds that discussions about the role and function of APSA Preprints are ongoing. Lastly, S. Smith and Super report on an ADVANCE grant awarded to four political scientists who will be partnering with APSA. The team plans to develop research-driven interventions that model, facilitate, and incentivize change to the climate and culture around sexual harassment and gender discrimination in political science.

\section{TREASURER'S REPORT}

Treasurer Thomas Pepinsky introduces the treasurer's report to update the Council on the association's financial position. Pepinsky reports that APSA continues to operate in sound financial shape. As of June 30, 2019, the total fair market value of all APSA's investments was \$39.5 million, with the most significant investment groups being the Congressional Fellowship Program trust portfolio which totaled $\$ 19.2$ million and the Trust and Development portfolio which totaled $\$ 18.2$ million. APSA is projected to be in line for the year with budgeted operating revenues of $\$ 8.53$ million, which includes draws from the 
CFP and Trust and Development Funds. Budgeted operating expenses are projected to be $\$ 8.5$ million, which includes carryover from the prior year for special projects. Operating net income is projected to be $\$ 100,000$ prior to investment earnings. The projection includes 2019 annual meeting revenues, which are expected to total $\$ 561,000$.

\section{FISCAL YEAR 2019-2020 BUDGET}

Burner introduces the proposed APSA fiscal year 2019-2020 budget for Council discussion and a later vote. Burner discusses the budget assumptions and explains changes in the budget system from the previous fiscal year, which should be helpful in the long term but make comparisons with the previous fiscal year difficult. Richards asks about funding for different APSA workshops, including the Teaching and Learning Conference and international workshops, and Super notes that the international workshops are largely grant funded. Pepinsky thanks APSA staff and notes that the changes to the budgeting process will be very useful in the long-term. Bowman, chair of the Audit Committee adds that the discussion with the auditors was very good and the audit report was positive.

\section{INVESTMENT POLICY}

Pepinsky introduces the Investment Policy developed by the APSA Investment Committee for Council discussion and approval. Pepinsky acknowledges that the committee has only been in place for approximately one year but has worked diligently over that time to develop a renewed investment policy. Pepinsky notes that APSA has a diversified and balanced approach that is reflected in the new investment policy.

The committee interviewed a number of potential investment advisers and elected to retain AndCo as investment advisers. Pepinsky introduces the updated investment policy developed by the committee and reports that the committee has not had the opportunity to fully discuss the issue of socially responsible investing, but the discussion is ongoing. R. Smith notes that further reports on socially responsible investing will be discussed in Executive Committee meetings and at the Spring Council meeting. Discussion elaborated on what constitutes socially responsible investing and if approval of the renewed investment policy can be deferred to the Spring Council meeting. R. Smith under- scores the importance of socially responsible investing. Further discussion of the investment policy is tabled until the Spring Council meeting when the proposed policy can be considered along with proposals regarding socially responsible investing.

\section{THELEN PRESIDENTIAL TASK FORCE REPORT}

Thelen introduces the report APSA Presidential Task Force on Women's Advancement in the Profession for Council to discuss and accept. Thelen explains that the task force worked diligently on all aspects of the report, including data collection efforts on women in the profession and analysis of mentoring efforts. A motion is offered to accept the report; the motion is seconded and approved unanimously.

\section{NATIONAL SCIENCE FOUNDATION UPDATE}

R. Smith introduces the topic of proposed changes to the National Science Foundation Political Science program to update Council. S. Smith begins discussion with an overview of proposed changes to the Political Science program by the Social, Behavioral, and Economic division of the National Science Foundation. The proposed changes involve splitting the political science program into two new programs (Security \& Preparedness and Accountable Institutions \& Behaviors). Separately, NSF program officers have encouraged APSA to apply for a grant to take on the current NSF Doctoral Dissertation Research Improvement Grant program.

Council discusses the implications of APSA assuming responsibility of the DDRIG program, including financial implications for APSA, cost sharing, branding, flexibility of grant awards, and transition funding. Shogan inquires as to who or what is driving the changes in NSF. S. Smith notes that the current NSF director, France A. Cordova, and current NSF senior leadership is not supportive of the SBE division and believes political science is harming the SBE division. Super notes that while there are a number of changes planned within the SBE division, political science is the only disciplinary program that would lose its disciplinary name or be split.

C. Smith expresses concern about the name changes allowing political scientists to be crowded out of NSF funding by economists or others. Titiunik, who is a member of the SBE advisory board, views the NSF changes as an effort to increase standing of political scientists and social scientists within NSF and encourage more interdisciplinary work. Wedeen expresses concern about the name "Security and Preparedness" and the securitization of political science research. Sjoberg asks about how the NSF changes impact the Political Science Graduate Research Fellowships and Super and S. Smith indicate that this is unclear. Pepinsky notes that the name change may increase rather than decrease scrutiny because grant awards will seem more incongruent with names.

Shogan and C. Smith suggest a direct lobbying strategy. S. Smith notes that APSA has begun some lobbying efforts and has hired Arent Fox as a lobbying firm. He further reports that lobbying efforts have so far focused on goodwill efforts and promoting political science to Congress. R. Smith notes that initial lobbying efforts have been well-received. Yanow and Sinclair-Chapman express concern about how eliminating political science from NSF may embolden countries in eliminating political science from curricula or university programs. Goren inquires how APSA is making members aware of the change. S. Smith notes that the change has been tweeted about and been mentioned in the APSA newsletter. Sjoberg expresses concern about increased scientization and securitization of political science driven by the NSF name change. Crescenzi notes that it will be more difficult to reverse the name change than to stop it. R. Smith reports that the proposal will be discussed at a Friday panel with NSF representatives.

\section{RESOLUTION ON ACADEMIC FREEDOM IN TURKEY}

R. Smith introduces a resolution regarding academic freedom in Turkey for Council vote. Yanow moves to approve the resolution; motion is seconded and approved unanimously.

\section{JPSE EDITORIAL TEAM RENEWAL}

S. Smith introduces the proposal to renew the term of the JPSE editorial team. S. Smith reports that JPSE editorial staff requested a two-year renewal to the current four-year term. He adds that a committee reviewed the renewal request and unanimously recommended the renewal. Gurstelle notes the review committee found that JPSE has improved on all measures under the current editorial team. Sjoberg moves to approve the two-year renewal; motion is seconded and approved unanimously. 
REPORT ON JOURNAL DATA COLLECTION

Wolbrecht introduces a report from the Publications Policy Committee about journal data collection. She reports that since December 2017, all authors and co-authors have been asked questions about themselves, their institution, and the field and methodology of the paper when submitting to $P S$, Perspectives, and APSR, following a Fall 2017 Council meeting decision. Wolbrecht notes the purpose of this effort was to better track patterns in submissions, rejections, and acceptances through the publications process, especially potential patterns of bias. She notes that the Publications Committee recommends an ad hoc committee be formed to analyze the data after two years of data has been collected, with the hope of a report to be published in March 2020. This survey is integrated into APSR, PS, and Perspectives submissions but is not yet used for JPSE.

McClain expresses concern regarding available ethnicity responses grouping Asians and Asian Americans together. Wolbrecht and Super note that APSA does not gather citizenship data, so making those distinctions can be difficult. C. Smith, Hooker, and Sjoberg express concern about how the lack of a question about sexual orientation might be interpreted by the LGBT+ community. Super and Wolbrecht acknowledge the complications of asking a possible identifying question and note that they consulted with the LGBT status committee on whether to ask a question regarding sexuality or gender identity when the data collection effort was organized. Mealy reports that the current LGBT status committee would be interested in hearing from and working with the Publications Committee. Martin expresses interest in including disability status in the data collection. Martin asks about the possibility of moving toward a centralized data collection methodology. Wolbrecht and Gurstelle reply that this would be ideal but is not currently possible. Council expresses interest in forming an ad hoc committee that is charged with creating a report that analyzes the data collected. Wolbrecht notes the Publications Committee will continue to examine which questions should be asked, including ethnicity and country of origin, disability status, and questions of gender and sexuality.

RELATED GROUPS POLICY

\section{PROPOSAL}

Hooker introduces a proposal from the Conferences and Meetings Committee to introduce a new policy governing related groups. Hooker explains the policy would establish a 35-member requirement for related groups and alter the panel allocation formula for related groups to be based on submissions as well as attendance. The policy would introduce the possibility of a nominal fee to be introduced in three years, review of new related groups by APSA Council, and allow APSA to monitor related group memberships. Hooker clarifies the goal of the proposed policy is to facilitate greater communication between APSA and related groups. She notes that, if activity in a related group is high, related groups may be encouraged to become a section. Hooker indicates the policy was formed with input from related groups.

Yanow expresses concern about how the policy will affect existing related groups. Hooker replies that existing related groups will have a transition period to conform with the policy, while any new groups must conform with the policy when formed. McConaughey notes that panel allocation for related groups is based on attendance, but the new policy would create a formula based on both attendance and submissions, to encourage additional connections to APSA members. Kocher adds that all related groups would continue to receive at least one panel. S. Smith notes that adding a submission piece into the panel allocation formula makes it easier for individual related groups to increase the number of panels allocated to them. Pepinsky, Van Vechten, and Yanow express concern about how the proposal may affect certain groups, especially niche groups that may not have membership to reach a 35 -member threshold and international attendees. Super suggests that certain small related groups may be better served signing a memorandum of understanding with APSA. Kocher notes that the proposal includes a threeyear review period to address concerns that may arise. Jackman moves to approve the proposed policy; motion is seconded and passes with two abstentions.

\section{REPORT OF THE AD HOC COMMITTEE ON AWARDS PROCEDURES AND RECOMMENDATIONS}

Hooker introduces the report and policy recommendations of the Ad Hoc Commit- tee on Awards Procedures and Recommendations for Council approval. Hooker notes that the Ad Hoc Committee was tasked with creating a policy to address questions of transparency in the selection process for public service-focused awards as well as increasing the pool of nominees. Hooker explains that the proposed policy attempts to relieve pressure on award committees to give an award each year, provide executive committee oversight of the award committees, and create a process for the association to rescind awards. Martin expresses concern that the policy does not apply equally to all award committees and only focuses on public service awards. Richards suggests that the policy narrows the possible pool of nominees, and that the proposed policy on rescinding awards could be perceived as ideologically biased and does not clearly define all of its language, particularly around the idea of misconduct. Hooker notes that the language around misconduct is an outgrowth of the harassment policy. Sjoberg agrees that the granting of awards based on public service is always ideological, and, as a result, so is any policy that allows the rescinding of those awards. Sinclair-Chapman notes that she does not believe that the policy is ideologically based. She continues by noting that the committee has done their due diligence is providing a policy that gives APSA oversight of an APSA award. Wedeen asks why awards based on public service are given at all, because they have the potential to be ideologically biased, and notes that requiring a political science degree limits the pool of deserving public servants. GarciaBedolla suggests that the policy should be broadened to all APSA awards. S. Smith replies that the requirement of a $\mathrm{PhD}$ in political science was added in order to ensure the awardee was not only a public servant but also had a connection to political science. He further notes that the policy can be expanded to all awards but then the review committee indicated in the policy may need to be separate rather than relying on the Executive Committee.

Pepinksy notes that the policy will make award committees more transparent in the conferring of awards. He suggests that the rescinding of an award based on violations of human rights should be struck from the policy because it is too specific and suggests the policy was created in response to the Condoleezza Rice situation. SinclairChapman notes that human rights were an important issue raised previously and were 
included as a result. Simpser agrees with Pepinsky and also suggests that the policy should not be extended to all APSA awards. Encarnacion suggests that the interpretation of who can receive the award should be expanded to include state and local officials. Shogan suggests broadening the award committee to include members of the civil service or departments that may not be currently included.

Yanow moves to amend the policy to apply Executive Committee review of all career awards; the Ad Hoc Committee does not accept the amendment as a friendly amendment, no second is brought, and the motion fails. Sjoberg moves to separate the review portion and the rescission portions of the policy and vote on them individually; the motion is seconded and approved.

R. Smith notes that there are now two proposals under consideration: one to provide for review of public service awards by the Executive Committee and one to create procedures for rescinding awards. Hooker proposes an amendment to restore the original proposal by the committee, removing the approved amendment. Simpser notes that the language does not allow for clear separation of the issues and the entire proposal should receive a vote. Martin moves to amend the policy on rescinding awards only be applied to awards given moving forward and not to awards that have already been given; the Ad Hoc Committee does not accept the amendment as a friendly amendment. The motion receives a second, but it fails on a vote. Pepinsky moves to amend the policy to replace language around human rights violations with "whose public record or actions in office run counter to the principles of the association and/or the award." The motion is seconded, discussion occurs, and the motion fails with a vote of 12 in favor, 14 opposed, and three abstentions. Consideration returns to the proposed amendment to restore the original proposal by the committee, removing the approved amendment. This amendment is approved with 26 in favor, one against, and two abstentions. Consideration returns to the original motion as amended, which now means the committee's original recommendation. The question is called and the vote on the Ad Hoc Committee's proposal as amended is approved.

\section{RBSI CAPITAL CAMPAIGN}

S. Smith introduces the report on the status of the RBSI Capital Campaign to update the
Council. S. Smith provides background on the RBSI Capital Campaign. In 2013, Council approved a \$2.5 million fundraising goal for the RBSI program. In 2016, APSA launched the RBSI Capital Campaign; it now has $\$ 525$,0oo remaining in its goal. Super and Mealy thank Paula McClain for her efforts and time leading the RBSI program.

\section{STRATEGIC PLAN}

S. Smith introduces the new APSA strategic plan. S. Smith provides background on the strategic planning process. APSA adopted a strategic plan in 2016 for a three-year period of 2017-2019. APSA is adopting a new strategic plan for the period of 2020-2022. The major focus of the new strategic plan was innovative programming, along with better serving members. S. Smith highlights certain strategic priorities such as: public engagement and advocacy, diversity and inclusion, and opportunities around innovation in the annual meeting.

Garcia-Bedolla suggests including the climate of association activities in the diversity and inclusion section. Richards suggests that the mission statement is research-focused and would like to see an addition regarding the teaching and education of political science. Richards asks about the possibility of streaming portions of the annual meeting to allow those who cannot attend the meeting to still participate. S. Smith notes that at the Spring Council Meeting there may be discussion of sustainable practices at the annual meeting. He adds that he has been approached by members who want the annual meeting to be available virtually to reduce travel to the annual meeting for the purpose of reducing adverse impacts on the climate and environment. Super acknowledges that streaming mechanisms are available and APSA is considering piloting streaming options. She continues by noting that the research team will calculate carbon offsets based on meeting location and method of travel.

\section{REPORT OF THE AD HOC COMMITTEE ON ASSOCIATION POLICIES AND PROCEDURES}

Shogan introduces the report of the Ad Hoc Committee on Association Policies and Procedures to update the Council. Shogan reports the committee was guided by three questions: what range of sanctions should APSA be able to exercise in relation to professional misconduct; should APSA employ third party investigators to assist with such types of investigations; and who should review such results and issue sanctions? Shogan further notes that the committee discussed exactly what constitutes professional misconduct. Discussion on these matters will continue and the committee will develop recommendations. R. Smith commends the committee, Council, and APSA for trying to address these issues.

\section{REPORT OF THE AD HOC}

\section{COMMITTEE ON HUMAN SUBJECTS} RESEARCH

R. Smith introduces the report of the Ad Hoc Committee on Human Subjects Research. S. Smith notes that the report and its appendices are posted on the APSA website with members encouraged to comment on the report. He adds that the report is meant to be part of the Ethics Guide. Barreto reports that the policy is meant to guide research to be conducted in an ethical manner but not to be binding. The Council discusses the implications of the report on researchers, institutions, and IRBs. R. Smith notes that the work of the Ad Hoc Committee is an ongoing process and the Council will consider an updated report at the Spring 2020 meeting.

\section{COMMITTEE UPDATES AND REPORTS}

Hooker, chair of the Conferences and Meetings Policy Committee, provides updates on the work of the committee. She notes the major work of the committee has been the formation of the new related groups policy. Further work will continue regarding the issue of "manels." She concludes the update by suggesting the Ad Hoc Committee on Award Procedures be reconstituted with a new chair to address some concerns that had been expressed regarding the policy.

Encarnacion, chair of the Membership and Professional Development Policy Committee, provides updates on the work of the committee, including consideration of guidelines regarding contingent faculty. He finishes the update by thanking the committee members and APSA staff.

Garcia-Bedolla, member of the Publications Policy Committee, provides updates on the work of the committee. GarciaBedolla reminds Council of the report on journal data collection delivered earlier in the meeting. She concludes by acknowledging the continuing work on the committee regarding the online journal.

Sinclair-Chapman, chair of the Public 
Engagement Policy Committee, provides updates on the work of the committee. She reports the committee has been focused on how evolving notions of public engagement can be used in tenure and promotion decisions. The committee is working with the APSA staff on developing clear definitions of public engagement and determining how public engagement is used and understood by those in the discipline. Sinclair-Chapman further reports that the committee has debated and will continue to discuss the new civic engagement award.

Van Vechten, chair of the Teaching and Learning Policy Committee, provides updates on the work of the committee. She reports that the committee will be reviewing the decision to hold TLC biannually and hold a TLC-at-APSA each year as more data becomes available on both events.
She expresses hope for the online teaching library to become active soon. Van Vechten further reports the committee is contributing to an initiative to rethink and reevaluate the undergraduate political science major.

\section{VOTE ON BUDGET}

R. Smith introduces the 2019-2020 fiscal year budget for a Council vote. Pepinsky moves to approve the 2019-2020 fiscal year budget; motion is seconded and approved unanimously.

\section{NEW BUSINESS}

As chair of the Rules and Elections Committee, Hooker notes some comments that the committee had received about the election process, specifically in relation to diversity, transparency, and uncontested elections. R. Smith notes that these frustrations have been long-standing, and APSA should periodically review the election process. $S$. Smith suggests a review of the election processes that were instituted when the new bylaws were adopted. Thelen and $\mathrm{R}$. Smith note that competitive elections often rely on name recognition, not merit, something APSA does not want to happen. R. Smith, S. Smith, and Simpser discuss alternative methods of election, including the nominating committee nominating more than one candidate for each position and explicit reservation of seats to fulfill institutional and demographic diversity. $\mathrm{McCo}$ naughey notes the general time frame of nominations and elections. She further indicates that the best method of getting more people to vote is word of mouth.

R. Smith adjourns the meeting. 